\title{
Natural Conversation Reconstruction Tasks: The Language Classroom as a Meeting Place
}

\author{
Jun Ōhashi, University of Melbourne
}

\section{Introduction}

Key concepts in postcolonial discourse, such as Pratt's 'transculturation' and 'contact zone' and Bhabha's 'third space,' have influenced the goals of second/foreign language education in Europe, the U.S.A. and Australia. ${ }^{1}$ The goals of L2 teaching and learning have shifted from 'communicative competence,' which aimed at native-level competence, ${ }^{2}$ to 'intercultural competence,' which develops a cultural position in order to mediate the learners' cultures and the cultures of the target languages (Crozet and Liddicoat 1999).

In studies of colonial interactions, it has been noted that conquered or colonised peoples retain considerable agency in determining the extent to which they absorb elements of the dominant culture in which they must live; the version of the dominant culture that they adopt is, to a significant extent, one they have created themselves. Pratt (1991: 523) recognised and promoted this form of agency with the term 'transculturation,' originally coined by the Cuban ethnographer Fernando Ortiz in 1940 to describe cultural interactions and new cultural formations between the Spanish and African background communities in Cuba. ${ }^{3}$ Pratt observed that transculturation is at work in everyday situations, such as are found in classrooms, as well as in broader social contexts. Pratt also uses the idea of 'contact zone' to

\footnotetext{
${ }^{1}$ Second language and foreign language are not distinguished here. The term L2 (second language) is used throughout the paper.

2 'Native-level competence' is used here, rather than 'native-like,' which is commonly used in the studies of second language acquisition and applied linguistics in general. The assumption that speakers attain complete communicative competence as so-called 'native speakers' simply through birth or heritage has been challenged through the observation of experiences of diaspora and migration.

${ }^{3}$ Ortiz used the term to conceptualise changes in identities that arose through evolving social contacts, from 'hostility and suspicion through tolerance to cooperation' (1942).
}

PORTAL Journal of Multidisciplinary International Studies, vol. 6, no. 1, January 2009.

'The Space Between: Languages, Translations and Cultures': Special Issue edited by Vera Mackie, Ikuko Nakane, and Emi Otsuji. 
draw attention to the cultural contact points that develop between communities. Such zones are highly mobile, are not geographically fixed, and have a temporal aspect: "“contact zone" is an attempt to invoke the spatial and temporal copresence of subjects previously separated by geographic and historical disjunctures, and whose trajectories now intersect' (Pratt 1992: 7). This notion is particularly relevant in Australia, a multicultural society where migration and diaspora are significant features of the national cultural landscape. In other words, the contact zone is a useful concept for understanding any society where people with different ancestral roots are living together, and thus negotiating and co-constructing their multicultural identities. The 'contact zone' is the place where, for example, conversationalists negotiate and develop hybrid cultural forms and identities. It also has clear similarities with Bhabha's 'third space,' in which a dynamic process of identity formation denying 'primordial unity or fixity' is possible (1994: 37). Like the 'liminal stairwell,' a related concept from Bhabha, the 'third space' is an in-between place, an 'interstitial passage between fixed identifications [which] opens up the possibility of a cultural hybridity that entertains difference without an assumed or imposed hierarchy' (1994: 4).

These notions of 'transculturation,' 'contact zone' and 'third space' emerged from postcolonial discourse to inspire scholars in a variety of fields, including leading second language pedagogues in the U.S.A., Europe and Australia (Kramsch 1993; Byram 1997; Crozet, Liddicoat \& Lo Bianco 1999; Liddicoat et al. 2003, to name a few). The adoption of such concepts has led to a shift in the goals of L2 teaching and learning from 'communicative competence' to 'intercultural competence.' As Pegrum argues: 'Intercultural competence deemphasises the acquisition of a native-like identity and encourages the learner to carve out a 'third place' (Kramsch 1993) from which he or she will be able to negotiate and mediate between the native and target cultures' (2008: 137-138).

\section{Adapting the notions of transculturation and third space in L2 education}

The need for the shift towards emphasising intercultural competence in the second language classroom has been discussed by Zamel (1997:350) in terms of its potential to empower the decision-making of L2 learners. This approach can make allowances for the cultural variations associated with L1 and L2, promote 'intercultural competence,' and give prominence to the learners' own generative and inventive choices. In applying Pratt's discussion of transculturation to creative writing in ESL contexts, Zamel highlighted L2 learners' agency in adaptation, and dismissed traditional assimilation and acculturation 
models of learning that assume a need for those learners to conform to so-called "native speaker' norms. Zamel thus celebrates her students' diverse linguistic backgrounds and their contributions to redefining the objectives of language teaching. As she states: "variation of language and rhetoric, precisely because of their diverse perspectives and their startling, unexpected effect, can enrich our reading and transform our definition of what it means to be a better writer' (1997: 347). Zamel's argument is concerned with ESL and teaching and learning creative writing, but it is certainly also applicable in oral communication in L2 contexts, as part of the search for what it means to be a good communicator.

The leading pedagogues who have promoted intercultural language teaching (Kramsch 1993; Byram 1997; Crozet, Liddicoat \& Lo Bianco 1999; Liddicoat et al. 2003) use the term 'third place' in the context of L2 pedagogy. This term is semantically linked to the 'third space' conceptualised by Bhabha (1994), but in the context of language teaching it refers mainly to the L2 learning context as a symbolic 'meeting place' where L2 learners of various cultural backgrounds open their minds and freely explore interculturality, thus potentially transcending their cultural boundaries (Crozet, Liddicoat \& Lo Bianco 1999: 13). As Crozet and Liddicoat put it: 'The third place is not a fixed point which will be common to all learners, rather the nature of the third place is negotiated by each user as an intersection of the cultural perspectives of self and other' (1999: 181).

Transculturation takes place in the space between L1 and L2, where L2 learners strive to find their new hybrid identities. Liddicoat et al. (1999: 181) argue that the idea of 'developing a third place between the native linguaculture and the target linguaculture, between self and other,' should be promoted in intercultural language learning. The notion of the third place where transculturation takes place helps us move away from the assumption that one language has one culture, and, by extension, homogeneous and static patterns of behaviour and values. It also challenges the assumption that where two cultures meet, often in the context of native and non native speakers' conversations, the inevitable result will be dissonance, misfit, miscommunication and conflict. Such a view has been influential in studies of intercultural and interethnic communication (Shea 1994: 357), and indeed in interlanguage and crosscultural pragmatics studies. ${ }^{4}$

\footnotetext{
4 'Native speaker judgment' has been used to highlight and problematise L2 learners' non-native speaker-like performances. A study by Eisenstein and Bodman (1993), for example, included Japanese background speakers' responses to a discourse completion task, which asked: 'what do you say to your friend who offers to lend you \$500?' Two uncorrected examples were: 'Thank you very much. I hope you won't have trouble with this. I'll return it as fast as I possible' (184); and, 'I'm sorry. I'll always remember the debt of gratitude' (74). The
} 
The recognition of the third place in the context of second language education empowers learners, because it shifts the purpose of L2 teaching and learning from native-level production of the language, which disregards the learners' L1 and their preferences, to the 'intercultural competence' with which learners make choices that exceed cultural boundaries in intercultural contexts. Those who have been exposed to contextual understanding of other cultural ways of communication and world views (who says what for what purpose and intention on what occasion), have the potential to evolve into interculturally competent communicators who can embrace differences in cultural orientations and manage interactions with people outside their cultural boundaries.

The teaching of the Japanese language is an important example of the 'third place' in the Australian context given that, for the last two decades, it has been one of the most popular languages other than English (LOTE) across the educational spectrum, from primary to university level (Japan Foundation 2006). It has also been the most preferred LOTE choice among overseas students from Asia who are studying in Australia. Since the Japanese language serves as a common L2 for people from many backgrounds, it can help both domestic and overseas students explore intercultural language activities 'without an assumed or imposed hierarchy' (Bhabha 1994: 4). Promoting intercultural competence through Japanese language, or any other LOTE, can also redress some of the problems identified with the idea of intercultural competence (see Holmes 2006). ${ }^{5}$ Accordingly, in this essay, I introduce a language task that promotes intercultural competence in order to show how learners of Japanese reflect their L1 cultures in making sense of a naturally occurring Japanese conversation as a 'meeting place.'

researchers evaluated these responses as 'problematic,' 'difficult to interpret,' and 'uncomfortable and confusing.' Such labelling problematised the Japanese background speakers' performance as 'non-native like.' This kind of research approach still prevails in studies of interlanguage and cross-cultural pragmatics.

${ }^{5}$ Drawing on his interviews with fifteen Chinese overseas students at a university in New Zealand, Holms argues that 'intercultural competence' does not 'fully account for the power relations embedded in intercultural communication' (2006:19). She reports that cross-cultural exploration and mutual understanding were not always achieved between Chinese and New Zealand students. Some Chinese students commented on the challenges they faced when confronted by the racist and rude behaviour of New Zealand students. Such negative experiences may prevent Chinese students from accessing the intercultural competence that 'account[s] for the reconstruction and renegotiation of cultural identities" (Holmes 2006: 20). Given the increase of international students in the Australian and New Zealand higher education sectors, and their concomitant transformation of tertiary learning environments, intergroup boundaries - 'ingroup' and 'outgroup' - tend to be formed. While many positive cultural exchanges feed into these countries' multicultural identities, some negative consequences may have been inevitable due to the magnitude of overseas student numbers. With the privileged status of the English language as the international language and its associated history of colonisation, certain power relations are embedded in intercultural communication involving English. Holmes (2006:19) argues that this has not been fully accounted for in the current model of intercultural competence. Indeed, Japanese language as a preferred LOTE among overseas and domestic students can create a 'meeting place' where all students enjoy intercultural exploration without replicating the imposed power relationships of an English-dominant setting. 


\section{Natural conversation reconstruction tasks}

Natural Conversation Reconstruction Tasks (NCRTs) use a transcribed excerpt from a naturally occurring conversation from which some conversational turns are left out. The task asks L2 learners to consider and predict what would have been said in these missing turns. It employs the verbal protocol method (Ericsson and Simon 1993) in a wider sense to elicit participants' verbal responses to, and during, the task completion. ${ }^{6}$ NCRTs do not attempt to analyse the participants' cognitive and psychological processes. Rather they encourage participants to exchange their views freely in both an introspective and a retrospective manner. The task discussed in this article was originally designed for a crosscultural pragmatic investigation of thanking that involved native speakers of Japanese (Ōhashi and Ōhashi $2003)$; it is now used as one of our key teaching tools in teaching intermediate and advanced learners in tertiary education.

Conceptually, an NCRT provides a snapshot of a real life speech event that occurred at a certain point in time and place. In this task, learners try to make sense of the meaning of a conversation as a whole while predicting missing turns. Therefore, the provision of rich contextual information - such as the age, gender, and social status of the conversationalists, and what prompted the conversations - is crucial. The task provides learners with a 'virtual reality' in that they explore and articulate what they think they know about L1 and L2 norms. In our experience learners at first try to see the meaning of the conversations through the eyes of the conversationalists, and thus they try to imagine what, for example, a Japanese man of sixty might say in this specific context. However, as they actively explore possible options they find themselves considering what they would say in the given context by considering their own identity, social attributes and previous experience through interactions with others in similar speech events. Thus we often witness the active shifting of their viewpoint across cultural borders and social attributes such as gender and age. In other words, these learners explore cultural boundaries and the possibility of their own hybrid new identities.

\section{Thanking: balancing debt and credit, a symbolic settlement}

The NCRT on this occasion featured the 'traditional' Japanese way of thanking: o-rei. With this task I aimed to illustrate how L2 Japanese learners make sense of o-rei ritual conversations. As I have argued elsewhere (Ōhashi 2008a), o-rei is an aspect of specific Japanese culture norms in thanking episodes, whereby benefactor and beneficiary try to

\footnotetext{
${ }^{6}$ The verbal protocol method stems from experimental cognitive psychology, but its application in studies of second language acquisition has spread widely since the publication of Faerch and Kasper's paper (1987).
} 
achieve a symbolic settlement of the debt-credit equilibrium. The beneficiary insists on investing in thanking and/or apology speech formulae to compensate his/her debt incurred by a gift/favour received. The benefactor, meanwhile, tries to minimize the imbalance by denigrating the gift/favour giving. Both benefactor and beneficiary, then, jointly create this highly conventionalized o-rei ritual. Such orchestrated balancing acts continue until the benefactor changes the topic. Thus, the prolongation of 'arigato gozaimasu' (thanking speech formula) or 'sumimasen' (apology speech formula) plus 'ie ie tondemonai' (no, no, heavens no) conversational pairs is common, as illustrated below (Figure 1):

$\begin{array}{|ll|}\text { A: } & \begin{array}{l}\text { Sumimasen hontōni } \\ \text { apology formula really }\end{array} \\ \text { B: } \begin{array}{l}\text { Ie ie tondemo nai } \\ \text { no no heavens no }\end{array} \\ \text { A: } \begin{array}{l}\text { Arigatō gozaimasu } \\ \text { thanking formula }\end{array} \\ \text { B: } \begin{array}{l}\text { Ie ie } \\ \text { no no }\end{array}\end{array}$

Figure 1.

Theories of speech acts and politeness developed to describe the English language cannot predict the conversational organization and the choice of speech formulae in Japanese o-rei rituals. The o-rei rituals are oriented towards the norm of reciprocity, but this norm has not been fully integrated into the theories of speech acts and politeness (see Ōhashi 2008a: 2151).

A(5): Omiyage sumimasen ne hontō ni wa[zawaza]

present AP IP really going through the trouble

(I'm sorry [you went to such trouble for] the present, I'm really [grateful])

$\mathrm{B}(6)$ : [ie ie tondemo]nai desu

no no heavens no BE

(No, not at all)

A(7): Mōshiwakenai itsumo kiotsukatte moratte meiwaku kakete doumo AP always consideration $B$ receive trouble cause TF/AP (I'm really sorry...thanks, you are always so considerate)

B(8): Honno honno okuchi yogoshi. just just HON-mouth dirty

(literal translation: It'll just make your mouth dirty; or, in idiomatic translation: No, it's nothing special)

A(9): Iya iya tondemo nai desu yo no no heavens no BE IP (No, not at all.)

$\mathrm{B}(10)$ : Ashita wa? tomorrow Tm (What about tomorrow?)

$\mathrm{A}(11): \quad e[\because]$ ashita ano[::] well tomorrow well (Aahmm, well, tomorrow)

KEY: AP: apology formula; BE: copulative verb; B: benefactive verb; HON: honorific polite form; IP: interactional particles; Tm: topic marker; TF: thanking formula. 
The NCRT used for this study presents a number of the quintessential characteristics of Japanese $o$-rei rituals: first, the prolongation of 'thanking-denial' sequences; second, the use of apology formulae; and third, a sudden topic change (see Ōhashi 2008a: 2170). It is based on an edited version of an excerpt of an actual conversation, set out above (Figure 2).

The learners participating in the exercise are provided with detailed context including the age and sex of the conversational participants and what prompted the conversation. Here A (a male, 70 years old) and B (a male, 65 years old) are both occasional voluntary helpers in their local neighbourhood association (chōnaikai). They have been meeting regularly for the last five years. B has returned from a trip and called in on A, who was not at home. B left a bag of sasakamaboko (a kind of fish cake) worth ¥1,500 (¥80/A\$1) with A’s wife as a souvenir of the trip. The following day, A rings B, and the conversation used for the task takes place (Figure 2).

For the version of the conversation prepared for the NCRT, the beneficiary (A)'s turns are left out. The learners, in pairs, are asked to discuss and predict what A would have said in (5), (7), and (9). Eight advanced learners of Japanese were involved in this study. All of them started Japanese in secondary school and are enrolled in a Japanese language unit in the advanced stream at an Australian university. They have all stayed in Japan for periods of between 2 months and 12 months (average 4.2 months). Four of them are of Asian background (Chinese background speakers), and the other four are of non-Asian background (Anglo-European backgrounds). The learners, each paired with another person from a similar cultural background, were asked to reconstruct the conversation. They were also asked to think aloud while they determined what the Japanese speakers described in the task would have said in the missing turns. The whole process was audio-recorded, then transcribed. It was expected that

\begin{tabular}{|c|c|}
\hline $\begin{array}{l}\text { A(5): } \\
B(6):\end{array}$ & $\begin{array}{l}\text { ( } \\
\text { [ie ie tondemo]nai desu } \\
\text { no no heavens no BE } \\
\text { ( No, not at all ) }\end{array}$ \\
\hline $\begin{array}{l}\text { A(7): } \\
\mathrm{B}(8):\end{array}$ & $\begin{array}{l}\text { honno honno okuchi yogoshi. } \\
\text { just just HON-mouth dirty } \\
\text { (literal translation: It'll make your mouth dirty) }\end{array}$ \\
\hline $\begin{array}{l}\text { A(9): } \\
\text { B(10): }\end{array}$ & $\begin{array}{l}\text { ashita wa? } \\
\text { tomorrow Tm } \\
\text { (What do vou do tomorrow?) }\end{array}$ \\
\hline A(11): & $\begin{array}{l}e[\because:] \text { ashita ano }[\cdots \cdots \cdot] \\
\text { well tomorrow well }\end{array}$ \\
\hline
\end{tabular}

Figure 3. 
their comments would reflect their L1 cultural norms and their knowledge of Japanese language and culture. Figure 3 is an example of the NCRT. In the next three sections I discuss the learners' comments in the order of the missing conversational turns: $A(5), A(7)$ and $A(9)$.

\section{Turn A(5)}

All of the learners, bar one, chose the thanking formula, arigato gozaimashita for A(5). The following comments show their thought processes involved in determining their responses.

I don't know any other ways of thanking so... he would say dōmo arigatō gozaimashita.

It's obviously got to do something along the line of 'Thanks for the present from the other day.'

I think in Australian culture, if you are thanked you can say you are welcome, you can acknowledge thanking rather than denying it. In Australia older generations tend to deny it more. It gets annoying, why don't they accept and say thank you and you are welcome?

A is grateful since it's worth 1500 yen. A would not just simply say thank you, but will probably say along the line of, Hontōni dōmo arigatō (Thank you so much for your kind gift), maybe not dōmo just arigato gozaimashita. Because A is 70 and older, even though he is thankful he wouldn't be perhaps so polite because $\mathrm{B}$ is younger saying, ieie tondemo naidesu.

In the original conversation, $\mathrm{A}$ in (5) chose to use an apology formula, sumimasen ne. Only one student, who had spent 12 months in Japan, chose the apology formula. She commented that: 'I know that Japanese people often apologize in this situation, but we don't say that in English. More likely to say_-'thank you very much'—in English.'

Such comments suggest that after many years of formal language learning, apology speech formulae are not associated with 'Japanese thanking' by the learners. Both Asian and nonAsian background learners apply Australian norms to their target language, and the thanking formula is their preferred choice. It is also interesting to observe that the learners were at first paying a lot of attention to the conversationalists' social attributes, especially age, but gradually they started offering their own views based on their own individual attributes.

\section{Turn A(7)}

The learners commented on A(7) predominantly in English. This suggests, again, that their linguistic repertoire does not extend beyond the thanking formula arigatō gozaimashita.

No, you really have helped me and I really appreciate it. I don't know how to say it in Japanese.

Some learners chose to compliment the gift and express further thanks for the gift.

Maybe saying how he liked it a lot:

Honto ni oishikattadesu arigatō gozaimashita (It was really delicious. Thank you) 
Some learners chose from their repertoire in English.

You didn't have to do that, it was very thoughtful of you.

He would say something like, 'you don't have to do that.'

Sonna koto shinakutemo ii? (You didn't have to do such a thing)

In the original conversation, A(7) said: Mōshiwakenai itsumo kiotsukatte moratte meiwaku kakete dōmo (I'm sorry and thank you for always considering me). He chose an apology formula mōshiwakenai (literal translation: sorry, I have no excuse), and a benefactive verb, moratte (highlighting the act of receiving), to acknowledge B's consideration, and further apologized for having put B to the trouble of buying a souvenir. In other words, A invested in a lot of linguistic politeness to compensate for the debt incurred. While it should be noted that what the learners proposed for this turn, in English and/or Japanese, would not amount to conversational misfit or pragmatic dissonance, it is significant that none of them considered the option taken by A.

\section{Turn A(9)}

The interpretation of $\mathrm{B}(10)$ ashita wa? (Tomorrow?, plus topic marker $w a$ ) varied: 'Talking about tomorrow,' 'How about tomorrow?,' and, 'What are you going to do tomorrow?' Some participants tried to make sense of the 'A(9)-B(10) ashita wa?' sequence by attending to the speech act level of meaning. In other words, they interpreted this as an 'offer of repayment/ acceptance of the offer by specifying the date.' Some attended instead to the pragmatic level of meaning, hearing ashita $w a$ as the benefactor's signal to end the cyclical 'thanking-denial' routines, and thus, as intended, to save the beneficiary's as well as the benefactor's face.

Oishikattadesu (it was delicious), then B, I think, changed the topic because he has been thanked three times in a row and he has denied it twice. So rather than denying it three times he just changed the topic since he was embarrassed.

A(9) would say something like 'I am sorry to trouble you'; B said ashitawa just to end the gift giving procedure.

A(9): Sō dewa nai, arigatō gozaimashita (That is not true, thank you very much). B then changed the subject; probably he was uncomfortable and embarrassed with thanking, and also perhaps he felt that A had said enough according to the code of politeness. Three times is enough to say thank you and keep moving on and save embarrassment for both of them.

Those who interpreted this conversation in the speech act level, made sense of the 'A(9)$\mathrm{B}(10)$ ashita wa?' sequence as an 'offer of repayment/acceptance by specifying the date,' as in 'Can I make it up to you?,' 'I will take you out sometime', or 'Do you have time tomorrow?,' followed by ashita wa? (How about tomorrow?). Some learners commented that this interpretation was motivated by their knowledge of Japanese culture, which they 
expressed as, 'give something in return,' or 'in Japanese culture, you feel more obliged to give something in return when you receive a present.' A Chinese background speaker commented that 'Japanese culture is similar to Chinese culture, where if you receive a present you have to repay the favour and gratitude.' Some learners sensed that there was a rudeness in this interpretation of 'an offer of repayment/how about tomorrow?,' saying, 'but that's not right, and I think it's rude,' and, 'actually I don't think it's polite to say ashita wa straight away.'

However, in the original conversation, A(9) had a different goal, a pragmatic one. He actually said iyaiya tondemonaidesu yo (No, not at all) in reacting to $\mathrm{B}(8)$ who had denigrated the gift (literal translation: It'll make your mouth dirty). Thus, B(10) ashitawa (tomorrow?) has no sequential relevance to $\mathrm{A}(9)$. In fact, this ashita wa can be interpreted as a sudden topic change to end the cyclical o-rei ritual and therefore save embarrassment for both the beneficiary and the benefactor.

Other comments made by the learners refer to their beliefs about what is required in their L1 in a similar situation in comparison to what they believe to be the case in the L2. The NCRT inevitably caused the learners to attend to both their L1 cultural norms and their knowledge of Japanese language and culture. In other words, the learners found themselves transcending cultural boundaries in order to come to a mutually satisfying understanding of the NCRT. The teaching method thus provided them with a 'meeting place' where intercultural exploration could take place.

\section{Thanking and use of $L 1$ cultural norms}

As research on cross-cultural pragmatics looking at naturally occurring conversations increases, we gain better understanding about particular politeness orientations in various languages. For example, Hassall (2002) reports that Australian learners of Bahasa Indonesia thank significantly more than Indonesians themselves. It appears that the learners apply their Australian cultural norms and conversational patterns in deciding when and how to thank in Indonesian. Koutlaki (2002) offers a strong counter-example in discussing how expressions of thanks are used profusely in refusing an offer in Persian. She states that an 'offering-thanking' conversational sequence serves the purpose of enhancing face for both interlocutors.

According to her, the formulaic expression qabeli naedare (it's not worth anything) is used by shopkeepers to ritually refuse payment; the customer will then express thanks for the offer but insist on paying. The sequence may be repeated a number of times (Koutlaki 2002: 1753). 
In the task reported above, the learners used their L1 cultural norms to make sense of Japanese $o$-rei thanking. Yet most students, including Chinese background speakers, referred to and applied Australian norms; in other words, they tried to work out the Japanese conversation with Australian norms in mind. However, the Chinese background speakers demonstrated some ability to compare Japanese and Australian culture from the 'outside' vantage point of Chinese culture. For the Chinese background speakers, Japanese language is at best their third language. Speaking Chinese at home and living in an English-speaking country, they have direct personal awareness of negotiating different sets of cultural values. One of the Chinese background speakers commented: 'In Australia, I don't think people focus on the present so much, they talk more about the person, how was the trip, how was the weather. Talking about and listening to how B enjoyed his trip is an indirect way of showing A's gratitude.'

Another Chinese background speaker sees Japanese cultural norms as similar to Chinese customs: 'Japanese culture is similar to Chinese culture where if you receive a present you have to repay the favour and gratitude.' However, the learners from non-Asian backgrounds offered similar comments based on their current level of understanding of Japanese culture: 'In Japanese culture, you feel more obliged to give something in return when you receive a present.' Two of the non-Asian background learners commented on the prolongation of 'thanking-denial' sequences in Japanese thanking as distinct from Australian English. They came across similar o-rei rituals during their stay in Japan:

I think there is a set of codes in Japanese culture. There are certain expectations, souvenirs are expected, 'thank you so much'- 'oh, no, no' is extended.

'Thank you so much'_-'no no, it's nothing'—'no no, thank you,' is particularly Japanese.

Of these, the first student has stayed in Japan for twelve months and the second for four months. The length of the participants' exposure to the L2 environment may be a guide to their possession of such knowledge. But it is the participants' awareness of pragmatics and the quality of teaching input that are critical for their ability to formulate certain hypotheses. As Crozet and Liddicoat suggest, culture must be taught explicitly: 'culture is not learnt by osmosis, it requires an intellectual effort because culture is not readily accessible to be noticed' (1999: 116).

\section{Implications for teaching}

The NCRT can be useful for teachers to find out the thinking processes of their learners. This 
will enable teachers to develop more appropriate teaching materials. Furthermore, with NCRTs learners are made aware of culture-specific aspects of L2 in relation to their L1. The learners' comments noted in this paper suggest that the NCRT can also be a useful tool to raise learner awareness about the pragmatic features of both L1 and L2. Kasper (1997) advocates the necessity of consciousness-raising activities and subsequent communicative activities in L2 pragmatic teaching. Thus, an excerpt from real world conversations in the form of a NCRT is desirable; it allows learners to explore the third place and help them achieve intercultural competence. NCRTs can be designed to teach other cultural differences in other languages as described in the abovementioned studies by Hassall (2002) and Koutlaki (2002). For example, a NCRT could feature a possible thanking episode in which native speakers of Indonesian would not thank in a similar situation. ${ }^{7}$ Some conversational turns in which thanking would be expected in accord with Australian norms could be left out, and the learners could be encouraged to guess the missing turns and make sense of the whole conversation. The teacher, then, would show the missing sequence to the learners. Students could be asked to discuss the gaps between what they guessed and the original conversation, and to make hypotheses about the speaker intention and social norms and values of the targeted speech community in Indonesia. The teacher could also ask about their preferred choices and explain the possible cultural implications of their choices. Some culture-specific ritualised conversations in Persian discussed in Koutlaki (2002) could also be taught using NCRTs.

More research on these lines is needed to expand our knowledge of what counts in a crosscultural sense as thanking, and indeed, other speech acts, and to take those speech acts into account in second language teaching. The NCRT can be employed to teach culturespecific phenomena and rituals and their underlying social norms. As such, the task encourages the learners to explore both L1 and L2 norms, so that their L1 cultural background becomes a significant resource to be included in discussing what are universal features and what are not. Therefore, in the use of NCRTs, the learners' diverse L1 cultural background is an added value rather than a challenge to overcome. The learners' comments I have analysed in this paper indicate that the NCRT enabled those learners themselves to discover what thanking is and what its crosscultural social meanings might be. Culturally diverse classrooms

\footnotetext{
${ }^{7}$ The NCRT is primarily intended for the intercultural exploration of language learners, and thus it is not suitable as role play material. As discussed throughout this paper, native-level competence and manner are not sought in the pursuit of intercultural competence. It is also important to note that a 'native-non-native' conversation may involve different expectations on the part of native speakers. Therefore it is not suitable for the learners to recite and memorise conversations that occurred at a particular time and space between particular native speakers.
} 
do not only increase the understanding of culture-specific patterns of communication; they also create mutual interest, curiosity, and respect between different cultural groups.

\section{Conclusion}

In this article I have suggested some ways in which NCRTs can be used to encourage learners' intercultural exploration and empower their decision making as they gain intercultural competence. Such tasks encourage learners to explore the intersections where language use, speaker intention, and L1 and L2 cultural norms meet. The NCRT method helps learners to become aware of socially expected patterns of communication in L1 and L2 in terms of speech act choices, formulaic expressions, sequential organization, and politeness orientation. The focus on the NCRT in this paper indicates that method's potential for helping learners to transcend their cultural boundaries, in this instance by overcoming their narrow understanding of 'thanking' as 'expressions of gratitude and appreciation' and by widening their crosscultural views of what counts as thanking. With the NCRT, and some subsequent explicit teaching on the social meaning of $o-r e i$, including the etymological meaning of o-rei and the importance, particularly among Japanese, of debt-credit equilibrium, learners will be able to engage in Japanese thanking episodes in a crossculturally appropriate manner, or make their own choices with better understanding of the possible implications of their linguistic and pragmatic choices.

I have illustrated one example of a NCRT in order to underline its potential use in promoting L2 learners' intercultural exploration. However, in actual implementation, multiple examples of thanking episodes in different contexts could be developed. Language learners need to be informed of diverse conversational patterns in L2 (as well as in their L1), and their changing nature - which is often led by younger generations - should also be discussed. As stated earlier, what counts as thanking, and the social meaning that accrues to it, differs markedly from culture to culture. Such meanings, moreover, are not immune to social change. Japan has experienced a major reformation since 1945, and what is commonly referred to as Westernization now prevails throughout Japanese society. Such historical trends have created a significant difference between older and younger Japanese generations in terms of patterns of behaviour and communication. It is therefore important to include more examples of thanking episodes in the NCRT to avoid simplistic overgeneralisation about the cultural protocols of everyday communication. ${ }^{8}$ A natural conversation database, then, potentially

\footnotetext{
${ }^{8}$ See Ōhashi (2008b) for examples of how young Japanese engage in thanking episodes.
} 
provides learners with an ideal learning environment in which they may discover how people outside their cultural boundaries manage interactions and human relationships.

Teaching L2 pragmatics should not simply aim at encouraging native-level production; it should also aspire to developing awareness of diverse patterns of communication and their meaning, as embedded in L2 culture, in a broader context of intercultural competence. This process gives learners numerous opportunities to reflect on their L1 culture and L2 knowledge and to express their individual preferences, beliefs and strategies for achieving positive human relationships as good communicators who are competent in intercultural communication.

\section{Acknowledgements}

I would like to thank the two anonymous reviewers and the editors for their insightful comments. I also thank Hiroko Ōhashi for allowing me to use her original idea of NCRT in the context of intercultural exploration.

\section{Reference List}

Bhabha, H. 1994, The Location of Culture, Routledge, London.

Byram, M. 1997, Teaching and Assessing Intercultural Communicative Competence, Multilingual Matters, Clevedon, UK.

Crozet, C., Liddicoat, A. 1999, 'The Challenge of Intercultural Language Teaching: Engaging with Culture in the Classroom,' in Striving for the Third Place: Intercultural Competence through Language Education, (eds) J. Lo Bianco, A. Liddicoat, and C. Crozet, Language Australia, Melbourne, 113-25.

Crozet, C., Liddicoat, A., \& Lo Bianco, J. 1999, 'Intercultural Competence: From Language Policy to Language Education,' in Striving for the Third Place: Intercultural Competence through Language Education, (eds) J. Lo Bianco, A. Liddicoat, and C. Crozet, Language Australia, Melbourne, 1-20.

Eisenstein, M. and Bodman, J. 1993, 'Expressing Gratitude in American English,' in Interlanguage Pragmatics (pp.64-81), (eds) G. Kasper and S. Blum-Kulka, Oxford University Press, New York.

Ericsson K A, Simon H. A. 1993, Protocol Analysis: Verbal Reports as Data, MIT Press, Cambridge, MA.

Faerch, C. and Kasper, G. (eds) 1987, Introspection in Second Language Research, Multilingual Matters, Philadelphia.

Hassall, T. 2002, 'Do Learners Thank Too Much in Indonesian?,' Australian Review of Applied Linguistics, vol. 24, no. 2, 97-122.

Holmes, P. 2006,'Problematising Intercultural Communication Competence in the Pluricultural Classroom: Chinese Students in a New Zealand University,' Language and Intercultural Communication, vol. 6, no. 1, $18-34$.

Japan Foundation. 2006, Survey Report on Japanese-Language Education Abroad 2006: Present Condition of Overseas Japanese-Language Education-Summary. Online, available: http://www.jpf.go.jp/e/japanese/survey/result/index.html (Accessed 1 November 2008).

Kasper, G. 1997, 'The Role of Pragmatics in Language Teacher Education,' in Beyond Methods: Components of Language Teacher Education, (eds) K. Bardovi-Harlig and S. Hartford, McGraw Hill, New York, 113-16.

Koutlaki, S. 2002, 'Offers and Expressions of Thanks as Face Enhancing Acts: Tae' arof in Persian,' Journal of Pragmatics, vol. 34, 1733-56.

Kramsch, C. 1993, Context and Culture in Language Teaching, Oxford University Press, Oxford.

Liddicoat, A., Crozet, C. \& Lo Bianco, J. 1999, 'Striving for the Third place: Consequences and Implications,' in Striving for the Third Place: Intercultural Competence through Language Education, (eds) J. Lo Bianco, A. Liddicoat, and C. Crozet, Language Australia, Melbourne, 181-87.

Liddicoat, A., Papademetre, L., Scarino, A., \& Kohler, M. 2003, 'Report on Intercultural Language Learning,' Department of Education, Science and Training, Canberra. 
Ōhashi, J. 2008a, 'Linguistic Rituals for Thanking in Japanese: Balancing Obligations,' Journal of Pragmatics, no. $40,2150-74$.

2008b, 'Thanking Episodes among Young Japanese: A Preliminary Qualitative Investigation,' Japanese Studies, vol. 28, no.3, 291-304.

Ōhashi, J., and Ōhashi, H. 2003. 'Orei and the Speech Act of Thanking: A Cross-Cultural Pragmatic Investigation Using Natural Conversation Reconstruction Tasks,' Paper presented at Eurosla 2003. Online, available: Edinburgh. http://www.hw.ac.uk/langWWW/eurosla/ (Accessed 1 November 2008).

Ortiz, F. 1940, Cuban Counterpoint: Tobacco and Sugar, trans. H de Onís, Duke University Press, Durham and London.

1942, 'On the Phases of Transculturation (From a Speech Made at Club Atenas in Havana, 12 December 1942).' Online, available: http://www.historyofcuba.com/history/race/Ortiz-2.htm (Accessed 29 July 2008).

Pegrum, M. 2008, 'Film, Culture and Identity: Critical Intercultural Literacies for the Language Classroom,' Language and Intercultural Communication, vol. 8, no. 2, 136-54.

Pratt, M. L. 1991, 'Arts of the Contact Zone,' Profession, vol. 91, 33-40. 1992, Imperial Eyes: Travel Writing and Transculturation, Routledge, London.

Shea, P. D. 1994, 'Perspective and Production: Structuring Conversational Participation across Cultural Borders,' Pragmatics, vol. 4, no. 3, 357-89.

Zamel, V. 1997, 'Towards a Model of Transculturation,' TESOL Quarterly, vol. 31, no. 2, 341-52. 